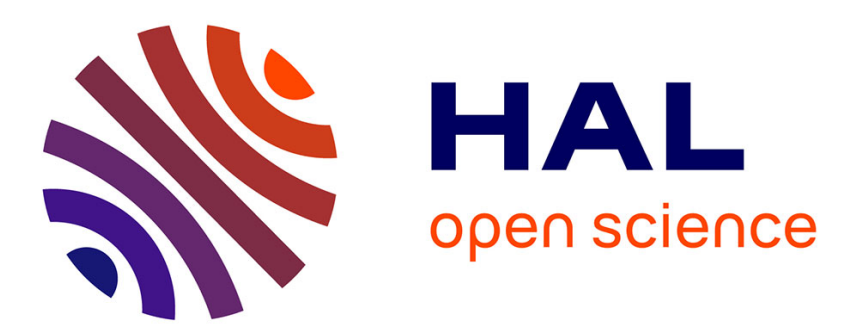

\title{
Research in Economics and Management in France: A bibliometric study using the h-index
}

Jean-Michel Courtault, Naïla Hayek, Eric Rimbaux, Tong Zhu

\section{To cite this version:}

Jean-Michel Courtault, Naila Hayek, Eric Rimbaux, Tong Zhu. Research in Economics and Management in France: A bibliometric study using the h-index. Journal of Socio-Economics, 2010, Volume 39 (Issue 2), pp. 329-337. hal-00489936

\section{HAL Id: hal-00489936 https://hal.science/hal-00489936}

Submitted on 7 Jun 2010

HAL is a multi-disciplinary open access archive for the deposit and dissemination of scientific research documents, whether they are published or not. The documents may come from teaching and research institutions in France or abroad, or from public or private research centers.
L'archive ouverte pluridisciplinaire HAL, est destinée au dépôt et à la diffusion de documents scientifiques de niveau recherche, publiés ou non, émanant des établissements d'enseignement et de recherche français ou étrangers, des laboratoires publics ou privés. 


\title{
Research in Economics and Management in France:
}

A bibliometric study using the h-index ${ }^{1}$

Jean-Michel COURTAULT, CEPN UMR 7115, Université Paris Nord

Naïla HAYEK, Université de Franche-Comté and Laboratoire Marin Mersenne, Université Paris I

Eric RIMBAUX, Université de Franche-Comté

Tong ZHU Université de Franche-Comté

\begin{abstract}
This paper presents an application of new measures of research excellence, namely Hirsch's index (2005) and derived indexes. It gives a ranking of French departments of Economics, departments of Management and Business schools based on the quality of the academic environment offered by these institutions using these measures. It argues that, since the bulk of the research is done by a very small number of researchers, a greater concentration of the best researchers seems necessary for France to achieve international visibility in Economics and Management.
\end{abstract}

JEL classification: A140

Keywords: h-index, g-index, publication activity

\footnotetext{
1 This paper was presented at the Workshop on the new challenges to the Economics of Business Schools and Universities of ESSEC and CEPN, Cergy-Pontoise, 4 and 5 December 2008 and we would like to thank Damien Besancenot, Glenn Ellison and Joao Faria for their comments. We also thank two anonymous referees for their very detailed and helpful comments.
} 


\section{Introduction}

A major concern of many countries is now to reform the universities and the research system. The economic success of the USA is attributed to its scientific supremacy. In order to direct reforms one needs tools that evaluate and measure the performances of institutions and researchers. Evaluation by peers is the traditional tool for evaluation but it is very costly. Recently, Great Britain through its Research Excellence Framework (replacing the older Research Assessment Exercise) supplements peer reviewing by quantitative information based on traditional bibliometric indexes such as the number of citations or the number of papers (Cf. J.-F. Méla (2009)).

This paper presents an application of new measures of research excellence, namely Hirsch index and its derived indexes. According to Hirsch (2005) a scientist has an index $\mathrm{h}$ if $\mathrm{h}$ of his p papers have received at least $\mathrm{h}$ citations each and his other $\mathrm{p}$-h papers have received at most $\mathrm{h}$ citations each. These indexes allow us to measure individuals' as well as institutions' research achievements. In particular, this paper gives a ranking of French departments of Economics, departments of Management and Business schools based on the quality of the academic environment offered by these institutions.

France is currently reforming its research and higher education system by imposing, among other things, minimum publication standards. This reform was initiated by two problems. In the innovation field, it is obvious one can only notice the failure of the policies of large projects in the Computer Science and the Biotechnologies areas. This failure is attributed to the top-down approach which is too centralized and which is followed in France. Although this approach has, in some other fields proved beneficial, such as Nuclear Plants, TGV, Airbus, Ariane... it is necessary for certain industries to have a bottom-up approach which is more decentralized (Cf. B. Coriat (2008)). In pure research, French scientists are much less cited than British and German ones (without taking the Americans into account): it is sufficient to look at the number of researchers highly cited per country on the ISI Web of Knowledge (158 for France, 258 for Japan, 259 for Germany, 376 for England, 4035 for the USA). If the number of citations measures the visibility or 
the originality of French research, it seems necessary to reform the system in such a way to incite the best researchers to stay in France or to come to France.

The Pécresse Act on governance of French universities, issued in august 2007, aims at increasing competition between research departments. It is therefore important to compute an empirical estimate of the quality of French research departments, since the incentives for academics to move from one department to a better one will increase. The incentives will be monetary bonuses and reductions in teaching loads. We concentrate on the possible evolution of research in Economics and Management.

A ranking of the best French business schools is periodically proposed by the business press but no such ranking exists for Universities. In those rankings, one takes into account the academic criteria (number of teachers with a $\mathrm{PhD}$, quality of publications as measured by CNRS, etc.). The ranking takes into account also non-academic criteria (such as wage level for the first job) which are more interesting for students. We propose a ranking of French departments of Economics, departments of Management and Business schools based solely on the quality of the academic environment offered by these institutions as measured by the h-index of Hirsch (2005). Since there is a strong correlation between the academic ranking and the final ranking of the business schools, the absence of non academic criteria should not bias our own ranking. Moreover, non academic criteria, notably wages, are known to be overestimated.

We also aim to measure the influence of competition on research in business schools. This could give an idea of the possible evolution of research in Universities' departments of Economics and Management. There is at the moment a great reluctance among French Universities to accept the mere idea of competition. We argue that the already existing competition among Business Schools has boosted research.

\section{Theoretical analysis}




\subsection{The h-index}

Classic measures of the quantity and quality of an author's research are the number of papers and the total number of citations. However, an author may have numerous papers not cited, or one single paper often cited. Clearly, a better measurement of the cumulative impact of research output is needed. Jorge E. Hirsch (2005) has proposed a new measure of scientific achievement. A scientist has an index $h$ if $h$ of his $p$ papers have received at least $h$ citations each and his other $p$ - $h$ papers have received at most $h$ citations each. Glänzel (2006) introduced the following alternative definition of the h-index as a solution to a maximization problem:

$$
h=\underset{j \in\{1,2, \ldots, p\}}{M}\left\{j: X_{j} \geq j\right\}
$$

where $X_{j}$ is the number of citations of the $j$-th most cited paper. If (1) has no solution we set $h=0$.

An optimal solution to (1) is such that $X_{h} \geq h$ and $X_{h+1}<h+1$. Since $X_{h}$ is a decreasing sequence this means that $h$ papers are cited at least $h$ times each and $p$ - $h$ papers are cited at most $h$ times (strictly less than $h+1$ ). Hence, both definitions are equivalent.

The h-index is a compound measure of productivity and quality, as measured by the number of citations received by the published papers. We assume that paper's citations are used as proxies for the paper's quality. Indeed, there is a good correlation between the prestige of a review and its impact factor (if a review is prestigious then more people will read it and cite extensively the papers published in it). If an author has a lot of citations it is presumably because his papers are published in prestigious journals. He may have also published high quality papers in lesser journals to shorten the publication delay or because of careless refereeing. Also we may assume that the number of publications is a proxy for scientific quality of a researcher. The h-index is neither entirely dependent on the number of citations nor on the number of publications. It synthesizes both measures as one needs to publish many papers with many citations each to have a high h-index. The higher the index, the greater the number of significant papers published by an author and the higher the significance of the papers. The underlying motivation being that none of the two measures taken 
separately can be considered reliable.

We may, alternately use Egghe's (2006) g-index. It's a variation of the h-index where cumulative citations are used instead of citations alone. Given a set of articles ranked in decreasing order of the number of citations, the g-index is the largest number such that the top g articles received, together, at least $\mathrm{g}^{2}$ citations. The g-index is the solution to (2):

$$
g=M_{j \in\{1,2, p, p\}}\left\{\dot{g}: \sum_{i=1}^{j} X X_{i} \geq j^{2}\right\}
$$

Both the g-index and the h-index give all the weight to the most cited papers than to the lesser papers. However the g-index better takes into account the citation scores of the top articles than hindex so that the quality of a researcher depends mostly on his best papers.

One of the main attractions of the index is its relative robustness. That is the h-index does not vary greatly if the number of documents included (e.g. if we exclude books or book chapters and consider articles only or if we exclude older papers) changes significantly. Neither the h-index increases significantly if the total number of citations increases. In particular, the h-index does not depend on the less interesting (i.e. cited) papers an author has published and, once a paper has reached h citations, the extra number of citations does not increase the h-index. In particular, this means that the h-index does not give undue weight to review papers.

If a researcher having an h-index with value $\mathrm{h}$ tries to increase his/her index to $\mathrm{h}+1$, he/she will often need to write more than one paper with $\mathrm{h}+1$ citations (since he/she may not have had already $\mathrm{h}$ papers with $\mathrm{h}+1$ citations). If one considers also that most papers ceased to be cited anymore after a relatively short lapse of time and that for any author the distribution of citations of his papers is very unequal, then a significant effort (both with respect to the quantity of papers published and their quality as measured by the number of citations received) has to be produced to increase one's $\mathrm{h}$ index.

Robustness may have two interpretations. First it means that a single paper cannot increase an index of scientific achievement by a big amount. Indeed, a single paper is not able to increase the h-index 
by more than 1 even if it has a lot of citations (even if the number of citations is greater than the initial $\mathrm{h}+1$ ). In contrast, if we take the total number of citations as the index of scientific achievement, it is often the case that a single paper is able to increase the index by a considerable amount. Second, robustness means that, in order to increase an index, it is necessary to add a significant number of papers significantly cited. A sufficient condition to increase the h-index is that the number of the new papers is at least as great as the initial $h+1$ and the number of citations of at least $\mathrm{h}+1$ of them is cited $\mathrm{h}+1$ times. In contrast, if we take the number of publications as an index of scientific achievement, then it is possible to increase the index by the addition of a single paper, be it cited or not.

Courtault and Hayek (2008) show that the h-index has an upper limit. As an author increases the number of his scientific production, the increase of his h-index is limited by the h-index of the new papers. That property is not shared by other indexes of scientific impact as the g-index of Egghe (2006). As an author increases the number of his scientific production the increase of his h-index is limited by the h-index of the new papers. If we consider a set of 3 papers $A$ with $X_{1}{ }^{A}=4, X_{2}{ }^{A}=3$ and $\mathrm{X}_{3}{ }^{\mathrm{A}}=1$ and the set of one paper $\mathrm{B}$ with $\mathrm{X}_{1}{ }^{\mathrm{B}}=8$ then $\mathrm{g}(\mathrm{AUB})=4>\mathrm{g}(\mathrm{A})+\mathrm{g}(\mathrm{B})=2+1$ whereas the increase in the h-index is at most equal to the h-index of the new set of papers B, $h(A U B)=3 \leq h(A)+h(B)=2+1$.

A significant number of papers significantly cited have to be published to increase the h-index.

This feature is particularly desirable for Social Sciences. Indeed the value of a social scientist cannot be fully evaluated with a single result, be it empirical (as with the discovery of a remedy for a fatal disease in the medical science) or theoretical (as with the proof of a famous mathematical conjecture in the mathematical science). Contrary to Nobel Prize philosophy, very few Nobel prizes in Economics were awarded for a single contribution (as the Black-Merton-Scholes formula for option pricing). Usually, they are awarded for several outstanding contributions, sometimes for their complete works, as it is the case with scholars who have initiated a new sub discipline.

The h-index is also a useful characterization when we try to compare the contributions of many 
scholars, since the evaluation process takes time. Researchers whose contributions are being evaluated earlier are not strongly disadvantaged relatively to researchers who are evaluated at the end of the investigation since the h-index does not depend significantly on the documents appearing after they were evaluated.

\subsection{Hirsch’s linear model}

In his original paper Hirsch (2005) illustrated his h-index with a particular model of publications and citations (which we dubbed linear model): let an author publish each year $p$ papers each being cited $c$ times each year. What will be the total number of citations and the h-index of this author after $n$ years? (The table corresponds to $\mathrm{p}=1$ )

Table 1: Hirsch's linear model for $\mathrm{p}=1$

\begin{tabular}{|l|c|c|c|c|c|}
\hline Citations & $1^{\text {st }}$ Paper & $2^{\text {nd }}$ Paper & $\ldots$. & $(n-1)^{\text {th }}$ Paper & $n^{\text {th }}$ Paper \\
\hline Year 1 & c & 0 & $\ldots$ & 0 & 0 \\
\hline Year 2 & c & c & $\ldots$ & 0 & 0 \\
\hline$\ldots$. & $\ldots$ & $\ldots$ & $\ldots$ & $\ldots$ & $\ldots$ \\
\hline Year $n-1$ & c & c & $\ldots$ & c & 0 \\
\hline Year $n$ & c & c & $\ldots$ & c & c \\
\hline$X_{t}$ & nc & (n-1)c & $\ldots$ & 2c & c \\
\hline
\end{tabular}

The most cited paper is the first published paper. The least cited paper is the last published. More generally, the $\mathrm{j}^{\text {th }}$ most cited paper has $X_{j}=(n+1-j) c$ citations, with $j=1, \ldots, n$. Assume $0<\mathrm{h}<$ $\mathrm{n}$. Then, $\mathrm{h}$ is uniquely defined by:

$$
\left\{\begin{array}{l}
\mathrm{X}_{\mathrm{h}} \geq \mathrm{h} \\
\mathrm{X}_{\mathrm{h}+1}<\mathrm{h}+1
\end{array} \Leftrightarrow \frac{\mathrm{c}-\mathrm{h}}{1+\mathrm{c}}<\mathrm{h} \leq \frac{\mathrm{c}+\mathbf{0}}{1+\mathrm{c}}\right.
$$

There is only one integer $h$ that verifies this inequality, since the difference between the boundaries of the inequality is equal to 1 and the interval is open on the left. Hence, $\mathrm{h}$ is equal to

$$
h=\left[\frac{c(n+1)}{1+c}\right] \approx \frac{c \quad n}{1+c}
$$

if $n$ is large enough.

The total number of citations of the author is: 


$$
\sum_{j=1}^{n} X_{j}=\frac{n(n+1) c}{2} \approx \frac{n^{2} c}{2} \approx \frac{(1+c)^{2} h^{2}}{2 c}
$$

where we used (4) to replace $n$.

Hirsch (2005) generalizes (4) and (5) for $p>1$. He assumes $p c>0$ and $c / p<n$. Then, for $n$ large enough:

$$
\begin{aligned}
& h \approx \frac{c}{\left(1+\frac{c}{p}\right)} n=n m \\
& \sum_{j=1}^{n p} X_{j} \approx \frac{\left(1+\frac{c}{p}\right)^{2}}{2 \frac{c}{p}} h^{2}=a h
\end{aligned}
$$

To sum up, the h-index combines quality with quantity of publications. It is easy to compute and may be used to evaluate individuals as well as journals or institutions. The h-index is robust. More papers do not imply directly a higher h-index. It is a measurement of scientific achievement and it does not depend solely on a few important papers.

\section{Empirical analysis}

\subsection{The data set}

We make use of four lists of researchers working in a French academic institution: Professors and lecturers in Economics who hold a position in a French university, Professors and lecturers in Management who hold a position in a French university, Permanent Professors and lecturers in Economics and Management who hold a job in a business school, Members of a CNRS (French equivalent for NSF) laboratory.

Note that a member of the teaching staff of a university is not always a member of a research center accredited to CNRS; a business school is not part of an university; some CNRS laboratory members are researchers only and do not teach; some CNRS laboratory members teach in institutions which are neither universities nor business schools (engineering schools, statistics schools..) and some of 
them are neither economists nor researchers in Management (they could be mathematicians, for instance).

Our observations are drawn from two different databases: Google Scholar and Scopus. Google scholar has a broader coverage but includes gray literature as well. Both have limited coverage of pre-1990 publications.

For each of these data bases, we calculate for approximately 6000 researchers a number of bibliometric indicators such as the total number of documents (articles, books and working papers) produced, the total number of citations received, the length of their scientific career, the h-index and the g-index ${ }^{2}$. For each query in the database, it is necessary to remove false positives due to namesakes, and to avoid false negatives, typically married women who may be listed with their married name or their maiden name, in the list or in the database.

\subsection{Test of Hirsch's linear model}

One could think that empirical studies using the h-index should take into account the length of academic career. For example, in his linear model Hirsch's shows that h-index increases linearly with time (Cf. Equation (6)). The objective of this section is to find whether we need or not to take into account the length of academic career. The results show that h-index does not depend on the length of one's career.

Equation (6) and (7) are tested on our data set with regressions:

c $i=t \alpha_{1}+\beta_{1} h^{2}+\varepsilon$

$h=\alpha_{2}+\beta_{2} n+\varepsilon$

where cit is the total number of citations of an author in the database, $h$ is the h-index of the author, and $n$ is the length of career of the author (time since his first publication ${ }^{3}$ ). The regression results are the following (Table 2):

\footnotetext{
2 Harzing's Publish or Perish software (downloadable at http://www.harzing.com/resources.htm) gives these indicators for Google Scholar whereas we had to compute them for Scopus.

$3 \quad$ For Google Scholar we used instead (Age - 30) as the data given by Harzing's program is usually very poor. We could not do such calculations for permanent professors of Business Schools as we do not have their age.
} 
Relation (8) between citations and the h-index holds in our data set, but not relation (9). Hirsch's linear model is rejected by the data. The hypothesis that papers are cited equally and regularly is clearly false. The fact that h-index is slightly correlated with the length of the career of a researcher instead of being strongly correlated may be due to the fact that data bases do not record well publications prior 1995. It also may mean that younger researchers are more productive than older ones ${ }^{4}$.

Table 2: Test of equations (8) and (9)

\begin{tabular}{|c|c|c|c|c|c|c|c|c|c|c|c|}
\hline Database & \multicolumn{5}{|c|}{ Google scholar } & \multicolumn{6}{|c|}{ Scopus } \\
\hline Data set & \multicolumn{2}{|c|}{$\begin{array}{l}\text { Department of } \\
\text { Economics }\end{array}$} & \multirow{2}{*}{$\begin{array}{c}\text { Business } \\
\text { school }\end{array}$} & \multicolumn{2}{|c|}{$\begin{array}{l}\text { Department of } \\
\text { Management }\end{array}$} & \multicolumn{2}{|c|}{$\begin{array}{l}\text { Department of } \\
\text { Economics }\end{array}$} & \multicolumn{2}{|c|}{$\begin{array}{l}\text { Business } \\
\text { school }\end{array}$} & \multicolumn{2}{|c|}{$\begin{array}{c}\text { Department of } \\
\text { Management }\end{array}$} \\
\hline $\begin{array}{l}\text { Dependent } \\
\text { variable }\end{array}$ & Citations & $\mathrm{h}$ & & Citations & $\mathrm{h}$ & Citations & $\mathrm{h}$ & Citations & $\mathrm{h}$ & Citations & $\mathrm{h}$ \\
\hline Constant & $\begin{array}{l}-1.84 \\
(1.34) \\
\end{array}$ & $\begin{array}{r}2.44 \\
(0.13) \\
\end{array}$ & $\begin{array}{l}-10.74 \\
(8.06) \\
\end{array}$ & $\begin{array}{l}-3.40 \\
(1.43) \\
\end{array}$ & $\begin{array}{l}1.39 \\
(0.08)\end{array}$ & $\begin{array}{l}1.17 \\
(1.54) \\
\end{array}$ & $\begin{array}{l}1.07 \\
(0.13)\end{array}$ & $\begin{array}{l}-5.26 \\
(12.80) \\
\end{array}$ & $\begin{array}{r}1.17 \\
(0.24) \\
\end{array}$ & $\begin{array}{r}2.65 \\
(1.15) \\
\end{array}$ & $\begin{array}{r}0.49 \\
(0.12) \\
\end{array}$ \\
\hline$h^{2}$ & $\begin{array}{r}4.31 \\
(0.17) \\
\end{array}$ & - & $\begin{array}{r}7.03 \\
(0.90) \\
\end{array}$ & $\begin{array}{r}4.89 \\
(0.32) \\
\end{array}$ & - & $\begin{array}{r}3.24 \\
(0.27) \\
\end{array}$ & - & $\begin{array}{r}5.36 \\
(1.07) \\
\end{array}$ & - & $\begin{array}{r}3.52 \\
(0.31) \\
\end{array}$ & - \\
\hline $\mathrm{n}$ & - & $\begin{array}{l}-0.016 \\
(0.006) \\
\end{array}$ & - & - & $\begin{array}{r}0.003 \\
(0.005) \\
\end{array}$ & - & $\begin{array}{r}0.093 \\
(0.016) \\
\end{array}$ & - & $\begin{array}{l}0.18 \\
(0.03) \\
\end{array}$ & - & $\begin{array}{l}0.07 \\
(0.02) \\
\end{array}$ \\
\hline $\mathrm{R}^{2}$ & 0.93 & 0.003 & 0.81 & 0.93 & 0.0002 & 0.875 & 0.10 & 0.77 & 0.19 & 0.93 & 0.10 \\
\hline
\end{tabular}

Standard errors in brackets. Standard errors are heteroskedastic-consistent estimates (see White, 1980).

\subsection{Pareto's Distribution}

The distribution of the h-index follows approximately Pareto's law. A similar result was found in Combes and Linnemer (2001) using another index of scientific achievement. We estimated the function:

$4 \quad$ If we consider that the output of a researcher rises and then declines, a quadratic regression would improve the fit of the model. Indeed such a regression improves the fit. 
where $\mathrm{N}(\mathrm{h})$ is the number of researchers with an h-index equal to or greater than a given value $\mathrm{h}$. The smaller the coefficient $\alpha$ and the greater the inequality of the distribution.

Table 3: Test of equation (10) - Dependent variable: $\log N(h)$

\begin{tabular}{|c|c|c|c|c|c|c|}
\hline Database & \multicolumn{3}{|c|}{ Google scholar } & \multicolumn{3}{c|}{ Scopus } \\
\hline Data set & $\begin{array}{c}\text { Department of } \\
\text { Economics }\end{array}$ & $\begin{array}{c}\text { Business } \\
\text { school }\end{array}$ & $\begin{array}{c}\text { Department of } \\
\text { Management }\end{array}$ & $\begin{array}{c}\text { Department of } \\
\text { Economics } \\
\text { Business } \\
\text { school }\end{array}$ & $\begin{array}{c}\text { Department of } \\
\text { Management }\end{array}$ \\
\hline Constant & 3,694 & 3,212 & 3,411 & 7,281 & 6,951 & 5,329 \\
$(0.13)$ & $(0.08)$ & $(0.12)$ & $(0.35)$ & $(0.29)$ & $(0.19)$ \\
\hline Logh & $-2,176$ & $-1,601$ & $-2,406$ & $-2,374$ & $-1,946$ & $-1,964$ \\
$(0.08)$ & $(0.13)$ & $(0.18)$ & $(0.13)$ & $(0.10)$ \\
\hline$R^{2}$ & $0.12)$ & 0,957 & 0,967 & 0,936 & 0,935 & 0,978 \\
\hline
\end{tabular}

Standard errors in brackets

The inequality of distribution is greater in Business Schools. There seems to be a specialization within each Business Schools where some people do more research while others do more teaching or other administrative work. There is also a similar specialization among Business Schools as we will see later.

Pareto's Law indicates that the bulk of the research is done by a very small number of researchers. According to Google Scholar, about 5\% of researchers (the elite in the sense of Allais (1974)) of any discipline realizes a quarter of the documents (articles, books or working papers) and collects half of the citations. According to Scopus, about 5\% of researchers of any discipline publish half of the total number of papers and collect $80 \%$ of the citations.

Those inequalities of distribution suggest that a sound human resource policy has to manage those $5 \%$ top researchers differently from the others 95\%. Adjustment of teaching duties according to one’s research output may be an important part of a contribution - retribution system that works well.

Our Scopus data indicates that half of the researchers in Economics departments, three quarter in 
Management departments and two third in Business Schools do not publish peer-reviewed papers. However we argue that it is still necessary that many researchers devote a significant portion of their time to research, even if it cannot be expected that any one of them will make great discoveries. The bulk of researchers do a useful job by distinguishing the important contributions with their citations.

\subsection{Stochastic Dominance}

Since one does not interact solely with the best researchers in a department, it is useful to have a global idea of the entire distribution of the quality of researchers in that department. Table 8, in the annex, contains the entire distribution of h-index as extracted from our databases. The following proposition helps analyzing this data.

Proposition $^{5}$ (Fishburn and Lavalle (1995)):

Let $\mathrm{F}$ and $\mathrm{G}$ be two distributions functions where the random variable $\mathrm{x}$ can take $\mathrm{n}$ values $\mathrm{x}_{1}<\mathrm{x}_{2}<$ $\ldots<\mathrm{x}_{\mathrm{n}}$.

$\mathrm{F} \geq_{\mathrm{FSD}} \mathrm{G} \Leftrightarrow \mathrm{D}_{1}\left(\mathrm{x}_{\mathrm{i}}\right) \geq 0$ for $\mathrm{i}=1, \ldots, \mathrm{n}$ where $\mathrm{D}_{1}\left(\mathrm{x}_{\mathrm{i}}\right)=\mathrm{G}\left(\mathrm{x}_{\mathrm{i}}\right)-\mathrm{F}\left(\mathrm{x}_{\mathrm{i}}\right)$

$F \geq_{\text {SSD }} G \Leftrightarrow D_{2}\left(x_{i}\right) \geq 0$ for $i=1, \ldots, n$ where $D_{2}\left(x_{i}\right)=\Sigma D_{1}\left(x_{j}\right) \times\left(x_{j+1}-x_{j}\right) \geq 0$ for $i=1, \ldots, n-1$

where $\geq_{\text {FSD }}$ (respectively $\geq_{\text {SSD }}$ ) stands for First (respectively Second) order Stochastically Dominates.

A distribution of the h-index $F$ first-order stochastically dominates another distribution $G$ if the proportion of people whose h-index is smaller than or equal to a given value $x_{i}$ is smaller for $F$ than $G$ for every value $x_{i}$. Everybody, who has a utility function increasing with respect to the h-index, will have greater expected utility under $F$ than under $G$. Similarly, any individual who has a utility function increasing and concave with respect to the h-index will have a greater expected utility under distribution $F$ which second-order stochastically dominates distribution $G$.

We found that distribution of h-index for the faculty of Economics first-order (second-order)

$5 \quad$ See also Courtault, Crettez and Hayek (2006). 
stochastically dominates the distribution of h-index for the faculty of Management (Business Schools), respectively. The first-order dominance holds true whether we use Google Scholar or Scopus data bases whereas second-order dominance does not hold with Scopus. The fraction of researchers having a low h-index is greater in Management departments than in Economics departments (for any value of the h-index). Hence, if you have a utility function increasing with respect to the quality of research then you should prefer working/studying in a department of Economics instead of Management. Second degree stochastic dominance reflects the greater inequality of research in Business Schools.

University Professors are better researchers than University Lecturers. Distribution of h-index for Professors of Economics first-order stochastically dominates the distribution of h-index for Lecturers. This is true both for faculty of Economics and Management and with both data bases. This tends to prove that research is a criterion for promotion in Universities. However this criterion for promotion is stronger among the faculty of Economics than with the faculty of Management. Indeed, for each level of the h-index $\mathrm{x}_{\mathrm{i}}$, we have

$\mathrm{D}_{1 \text { EconLect }}\left(\mathrm{x}_{\mathrm{i}}\right)-\mathrm{D}_{1 \text { EconProf }}\left(\mathrm{x}_{\mathrm{i}}\right)>\mathrm{D}_{1 \text { BusLect }}\left(\mathrm{x}_{\mathrm{i}}\right)-\mathrm{D}_{1 \text { BusProf }}\left(\mathrm{x}_{\mathrm{i}}\right)>0$

This means that first-order stochastic dominance between Professors and lecturers is stronger in Economics than in Management departments. This would tend to prove that University Lecturers in Economics who are doing more research than others tend to become University Professors more easily than University Lecturers in Management.

If we build the production frontier for research with two outputs, documents per researcher and citations per researcher. Research output is efficient in Business Schools and Economics Departments, both with respect to Google Scholar and Scopus data bases. Although Economics departments produce more research than Business schools they receive less citations, indicating that research in Economics Departments might be of a worse quality or less central.

However, inefficiency of research in Management Departments is strong. With a better 
management of research it should be possible to double (according to Google Scholar) the number of documents per researcher as well as the number of citations per researchers. According to Scopus, this inefficiency is even stronger, reflecting the fact that most part of research in Management Departments is written in French. It should be possible to multiply the number of papers and citations by 3.6 .

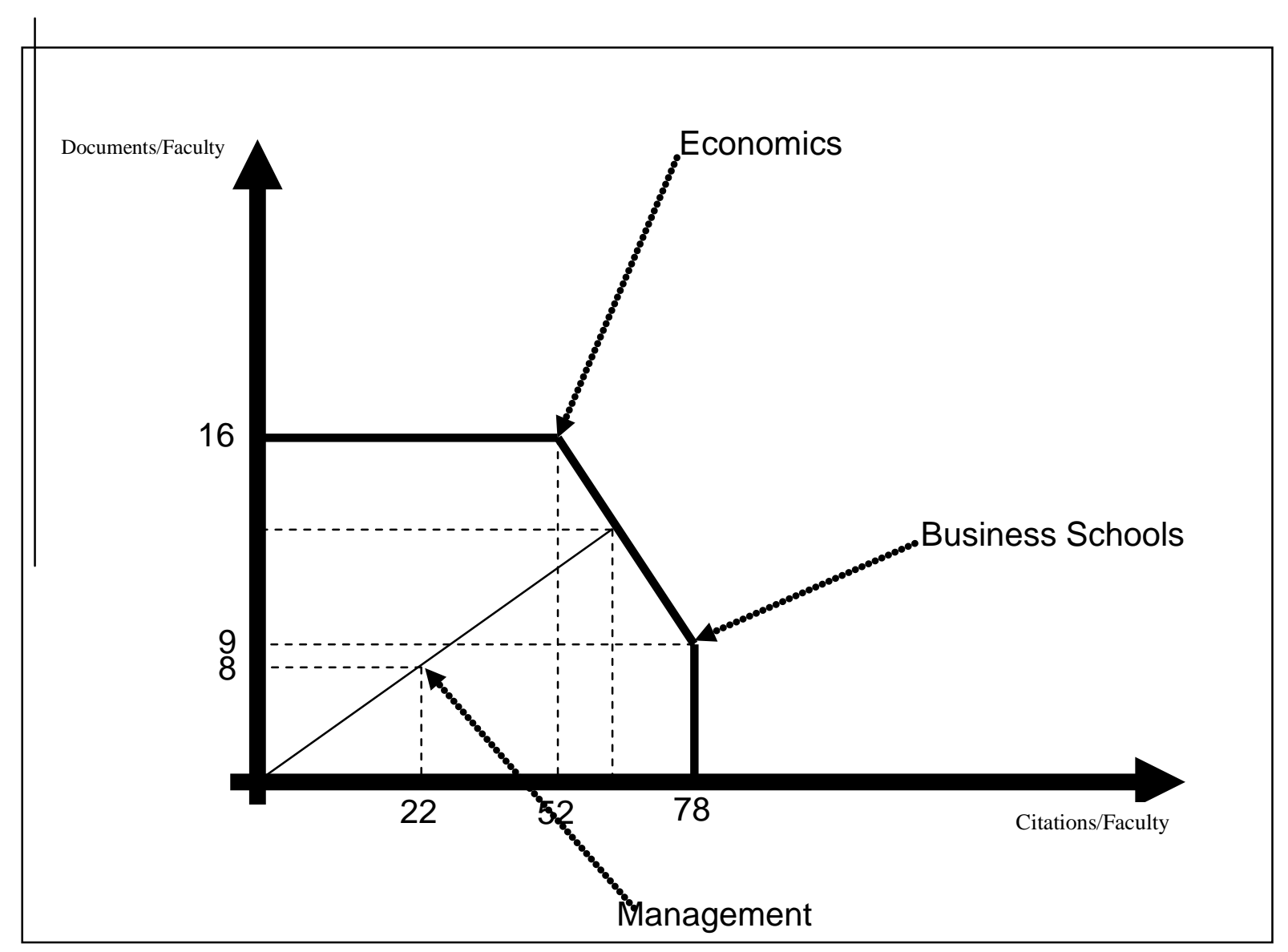

Graph 1: Inefficiency of Management departments as measured by Google Scholar

Research in Management Departments strongly needs to be reorganized. The reorganization could go through the assignment of economists and mathematicians on Management positions as the Quantitative Management Techniques can be taught by economists and mathematicians as well as managers. That's partly how Business Schools have significantly improved their performance in 
research. Among the elite professors (the top 5\%) of Business Schools 43\% for Google Scholar (38\% for Scopus) belong to the Economy-Finance Department or Logistics. Another possibility for improvement of research in Management Departments could be to increase the link between research and promotion.

\subsection{Ranking analysis}

We used the results to classify the departments of Economics and Management of universities, Business Schools and CNRS laboratories. For this purpose, we use another measure based on the hindex (respectively, g-index) which we denote $h^{\circ} \mathrm{h}$ (respectively, $\mathrm{g}^{\circ} \mathrm{g}$ ). Contrary to other studies using the h-index applied to institutions (Scientific Journals in particular) our $\mathrm{h}^{\circ} \mathrm{h}$ is not calculated as the h-index of the set of all the papers published by the members of this institution but rather is calculated in the following way: for each institution we can rank the staff in descending order of $h$ (or g) and then calculate the h-index of this set (or the $\mathrm{g}^{\circ} \mathrm{g}$ ).

An institution with rank $\mathrm{h}^{\circ} \mathrm{h}$ is such that $\mathrm{h}$ of its faculty has an $\mathrm{h}$-index greater or equal to $\mathrm{h}$ and the rest has an h-index smaller than $\mathrm{h}+1$. The higher the index the higher the number of important scientists this institution hosts and the greater the importance of those scientists. We may consider that an institution with higher $\mathrm{h}^{\circ} \mathrm{h}$ offers a better scientific environment. We prefer this ranking to ordinary h-index applied to all papers published by the staff of an institution for practical and philosophical reasons. On the practical side we should have to run Boolean research for the 6000 researchers, not an easy task especially with Scopus. On the philosophical side although Boolean research would have the advantage of avoiding double counting of papers written by coauthors belonging to the same institution it would be a measure of the h-index of the best two researchers of any institution. Therefore it would not be a very robust measure of the quality of academic environment of an institution especially in a time where best researchers should be more inclined to move. The main advantage of our $\mathrm{h}^{\circ} \mathrm{h}$ index is that it does not depend in an essential way on the most important scholar working in an institution. The $\mathrm{g}^{\circ} \mathrm{g}$ index tries to capture this influence. 
The top 10 Economics departments are the intersection of the best departments according to Google Scholar ranking $\left(\mathrm{h}^{\circ} \mathrm{h} \geq 5\right)$ and Scopus ranking $\left(\mathrm{h}^{\circ} \mathrm{h} \geq 3\right)$. Departments which did not verify both conditions were eliminated from the final list.

Table 4: Economics departments

\begin{tabular}{|l|l|l|l|l|l|l|l|l|l|}
\hline \multirow{2}{*}{ Universities } & \multirow{3}{*}{ Faculty } & \multicolumn{5}{|c|}{ Google Ranking } & \multicolumn{4}{c|}{ Scopus Ranking } \\
\cline { 3 - 11 } & Documents & Citations & $\mathrm{h}^{\circ} \mathrm{h}$ & $\mathrm{g}^{\circ} \mathrm{g}$ & Papers & \multicolumn{2}{|c|}{ Citations } & $\mathrm{h}^{\circ} \mathrm{h}$ & $\mathrm{g}^{\circ} \mathrm{g}$ \\
\hline Toulouse 1 & 64 & 3068 & 20866 & 10 & 22 & 487 & 3233 & 7 & 12 \\
\hline Paris 1 & 112 & 3001 & 11404 & 8 & 18 & 294 & 1078 & 4 & 7 \\
\hline Paris 10 & 55 & 1638 & 6879 & 7 & 15 & 198 & 805 & 4 & 6 \\
\hline Aix-Marseille 2 & 49 & 1036 & 3222 & 6 & 12 & 221 & 770 & 5 & 7 \\
\hline Strasbourg 1 & 30 & 818 & 3161 & 6 & 12 & 122 & 672 & 4 & 7 \\
\hline Paris 9 & 59 & 917 & 3785 & 5 & 11 & 222 & 1443 & 4 & 8 \\
\hline Lille 2 & 15 & 362 & 1965 & 5 & 10 & 70 & 360 & 3 & 6 \\
\hline Paris 2 & 38 & 600 & 1720 & 5 & 10 & 108 & 256 & 3 & 5 \\
\hline Paris 13 & 36 & 651 & 2044 & 5 & 10 & 59 & 267 & 3 & 4 \\
\hline Cergy & 22 & 460 & 1039 & 5 & 8 & 81 & 195 & 3 & 4 \\
\hline
\end{tabular}

The best department of Economics according to both rankings is Toulouse 1 (hardly a surprise). The second best department is more difficult to ascertain even though Paris 1 and Aix-Marseille 2 are good candidates. Half of the best departments are concentrated in Paris (Paris 1, 2 and 9) or near Paris (Paris 10, 13 and Cergy). We also found that the distribution of h-index of economists of the Paris region second-order stochastically dominates that of non-Paris economists.

It is quite surprising that the best department of Economics is not hosted by a single University of the Paris area, contrary to most other disciplines (in the hard sciences and social sciences alike). These findings explain the creation of the Paris School of Economics which aims to consolidate the leading research departments of the Paris region in a single institution, regardless of the University/ non university status of the departments.

The top 7 Management departments are the intersection of the best departments according to Google Scholar ranking $\left(h^{\circ} h \geq 4\right)$ and Scopus ranking $\left(h^{\circ} h \geq 2\right)$. Departments which did not verify both conditions were eliminated from the final list. 
Table 5: Management departments

\begin{tabular}{|l|l|l|l|l|l|l|l|l|l|}
\hline \multirow{2}{*}{ Universities } & \multirow{3}{*}{ Faculty } & Documents & Citations & $\mathrm{h}^{\circ} \mathrm{h}$ & $\mathrm{g}^{\circ} \mathrm{g}$ & Papers & Citations & $\mathrm{h}^{\circ} \mathrm{h}$ & $\mathrm{g}^{\circ} \mathrm{g}$ \\
\hline Paris 9 & 63 & 1026 & 4954 & 6 & 14 & 58 & 348 & 2 & 5 \\
\hline Grenoble 2 & 76 & 689 & 1725 & 5 & 9 & 35 & 136 & 2 & 3 \\
\hline Toulouse 1 & 39 & 512 & 2700 & 4 & 11 & 62 & 406 & 2 & 5 \\
\hline Aix-Marseille 3 & 46 & 577 & 1851 & 4 & 10 & 60 & 337 & 2 & 5 \\
\hline Aix-Marseille 2 & 24 & 294 & 946 & 4 & 8 & 57 & 560 & 2 & 5 \\
\hline Paris 1 & 63 & 622 & 1331 & 4 & 8 & 32 & 82 & 2 & 3 \\
\hline Rennes 1 & 53 & 406 & 901 & 4 & 7 & 19 & 28 & 2 & 2 \\
\hline
\end{tabular}

The best department of Management according to both rankings is Paris 9 (hardly a surprise too, although its supremacy is not so obvious according to Scopus). Contrary to Economics, most of the best Management departments are not located in Paris. Paris 9 seems to have absorbed the best researchers in Management in the Paris Region whereas this is not the case for Paris 1 with economists, in spite of its superiority in numbers.

More than half of the best departments of Management are in Universities where the department of Economics is among the best. However, researchers in Economics are not used to work with researchers in Management as a single united research team (and often they do not wish to). This prevents them to put forward competitive trainings against those of Business schools.

The top 9 Business Schools are the intersection of the best Business Schools according to Google Scholar ranking $\left(\mathrm{h}^{\circ} \mathrm{h} \geq 4\right)$ and Scopus ranking $\left(\mathrm{h}^{\circ} \mathrm{h} \geq 3\right)$. Business Schools which did not verify both conditions were eliminated from the final list.

Table 6: Business Schools

\begin{tabular}{|l|l|l|l|l|l|l|l|l|l|}
\hline \multirow{2}{*}{ Business Schools } & \multirow{2}{*}{$\begin{array}{l}\text { Permanent } \\
\text { Professors }\end{array}$} & \multicolumn{5}{|c|}{ Google Ranking } & \multicolumn{4}{|c|}{ Scopus Ranking } \\
\cline { 3 - 10 } & Documents & Citations & $\mathrm{h}^{\circ} \mathrm{h}$ & $\mathrm{g}{ }^{\circ} \mathrm{g}$ & Papers & Citations $^{\circ} \mathrm{h}^{\circ} \mathrm{h}$ & $\mathrm{g}^{\circ} \mathrm{g}$ \\
\hline INSEAD & 121 & 4420 & 76270 & 13 & 36 & 1200 & 20160 & 9 & 19 \\
\hline HEC & 106 & 2031 & 13948 & 9 & 20 & 404 & 2369 & 5 & 9 \\
\hline ESSEC & 106 & 2003 & 10200 & 7 & 18 & 403 & 2351 & 5 & 10 \\
\hline Edhec Lille Nice & 74 & 913 & 10168 & 6 & 15 & 129 & 5081 & 4 & 9 \\
\hline ESC Toulouse & 64 & 733 & 4510 & 5 & 11 & 118 & 712 & 3 \\
\hline EM Lyon & 76 & 581 & 2184 & 5 & 10 & 92 & 531 & 4 \\
\hline ESCP-EAP & 113 & 772 & 2143 & 5 & 9 & 115 & 619 & 6 \\
\hline Grenoble EM & 81 & 626 & 1481 & 4 & 9 & 134 & 441 & 3 & 6 \\
\hline $\begin{array}{l}\text { Ceram Sophia- } \\
\text { Antipolis }\end{array}$ & 50 & 260 & 640 & 4 & 7 & 53 & 250 & 3 & 4 \\
\hline
\end{tabular}

The best Business School according to both rankings is INSEAD. What is more surprising is that it 
ranks even higher than the department of Economics of Toulouse 1. Although most Business Schools did not have active research departments until recently, except INSEAD and ESSEC, they caught up and can now rival with the best Economics departments. This leads to an increasing competition, since jobs in Business schools are financially more attractive than in universities.

When we consider the entire distribution of the $h^{\circ} h$-index for Economics and Management departments we observe that they are log normally distributed whereas the same distribution for Business Schools follows Pareto’s Law. That is, the vast majority of Economics and Management departments makes research at an average level whereas a great number of Business Schools do not have active research at all and a few of them are doing very well.

There was a natural grouping (by market forces) of the best researchers from business schools towards a few institutions. We may consider that there is a small number of business schools that make high-level research while other schools are mostly teaching institutions. It is likely that we will witness the same phenomenon for the departments of Economics and Management of Universities except that this phenomenon is not entirely spontaneous but organized by the State. One of the main levers to achieve that goal is through CNRS accreditations.

There is a risk for the State of being captured by special interest groups as it needs assessment that it cannot ensure itself. History shows that the State has often encouraged the creation of monopolies rather than competition ${ }^{6}$. If some concentration of the best researchers seems necessary for France to achieve international visibility in economics it is essential that the academic market remains contestable. Indeed, the recent emergence of Economics departments such as Toulouse 1 and AixMarseille 2 shows that the creation of institutions of the highest level is based on few individuals, both researchers of international level and "Scientific entrepreneurs". If the university had not been contestable in France thirty years ago Laffont in Toulouse and Gérard-Varet in Marseille could not have created important international research centers.

6 Cf. Lever (2006) shows this for Theater in France. 
The top 9 CNRS Laboratories are the intersection of the best CNRS Laboratories according to Google Scholar ranking $\left(h^{\circ} \mathrm{h} \geq 8\right)$ and Scopus ranking $\left(\mathrm{h}^{\circ} \mathrm{h} \geq 4\right)$. CNRS Laboratories which did not verify both conditions were eliminated from the final list.

Table 7: CNRS Laboratories

\begin{tabular}{|l|l|l|l|l|l|l|l|l|l|l|}
\hline \multirow{2}{*}{ Laboratories } & \multirow{2}{*}{ Researchers } & \multicolumn{4}{|c|}{ Google Ranking } & \multicolumn{3}{c|}{ Scopus Ranking } \\
\cline { 3 - 10 } & & Documents & Citations & $\mathrm{h}^{\circ} \mathrm{h}$ & $\mathrm{g}^{\circ} \mathrm{g}$ & Papers & Citations & $\mathrm{h}^{\circ} \mathrm{h}$ & $\mathrm{g}^{\circ} \mathrm{g}$ \\
\hline UMR8545 PSE & 56 & 5150 & 51461 & 14 & 31 & 638 & 5927 & 7 & 14 \\
\hline UMR5604 GREMAQ & 62 & 4447 & 52017 & 13 & 28 & 670 & 6499 & 8 & 15 \\
\hline UMR8174 CES & 164 & 4853 & 18987 & 11 & 21 & 1032 & 4821 & 7 & 12 \\
\hline UMR2773 GRECSTA & 37 & 2327 & 22325 & 10 & 23 & 238 & 1714 & 5 & 10 \\
\hline UMR2959 GREGHEC & 70 & 2033 & 15470 & 9 & 21 & 434 & 2762 & 6 & 10 \\
\hline UMR6579 GREQAM & 51 & 2040 & 15179 & 9 & 20 & 452 & 2604 & 5 & 10 \\
\hline UMR7166 EconomiX & 94 & 2268 & 7709 & 8 & 16 & 262 & 699 & 4 & 5 \\
\hline UMR7176 PREG & 41 & 1313 & 6038 & 8 & 15 & 273 & 1049 & 5 & 8 \\
\hline UMR7522 BETA & 86 & 1621 & 6343 & 8 & 15 & 294 & 1286 & 4 & 8 \\
\hline
\end{tabular}

The best CNRS laboratory is either PSE or GREMAQ, the former being affiliated with Paris School of Economics and the latter with University of Toulouse 1. Note that CES affiliated with Paris 1 is better than GREQAM affiliated by Aix Marseille 2 whereas we saw that the departments of Economics of these universities are equivalent. The difference there is due to mathematicians. Indeed, a great part of the best scholars of CES are specialized in mathematical economics, in particular decision theory and general equilibrium theory. Although mathematical economics is not considered as central as it used to be (and as a consequence does not attract as many citations as the Economics of Contracts, for example, where there are so many active researchers) and although Paris 1 mathematicians do not generally specialize in the more popular field of mathematical economics (as Econometric Theory, Game Theory or Mathematical Finance) they nevertheless gained international recognition far beyond their economists’ colleagues. In all fairness to Paris 1 economists it should be said that their doctoral training has contributed more than any other doctoral training to turn out a considerable number of very able economists who contributed to disseminate all over French universities main stream economics. Indeed prior 1970, economics taught in French universities were almost exclusively heterodox or nationally oriented. Although, not without merits (indeed many heterodox themes, such as irrationality, are now included in 
mainstream economics) this teaching tended to isolate French universities' economists even more. Isolation was already very important as most people did their research exclusively in French. Although more and more economists publish nowadays in English there are still many French economic journals.

Half of the best CNRS laboratories are not affiliated with Universities but with a School either Business School or Engineering Schools. This shows the great importance of the engineerseconomists school in French economic research. Prior 1960 almost no research was performed in Economics and Management departments of French universities ${ }^{7}$. On the contrary there were a few engineers who did research internationally recognized such as Allais, Boiteux, Debreu, Divisia, Gibrat, Malinvaud, Massé, Roy, Rueff. Some important results bear their names. It is not clear whether their followers have been as successful as them.

\section{Conclusion}

Will the Paris School of Economics and Toulouse School of Economics succeed to emulate Harvard or other top US universities? Indeed, the ambition of the Paris School of Economics according to its former director Piketty is to "build a center of excellence at the level of the best institutions in the world economy (Harvard, LSE, MIT, Princeton, etc.) based on mobilization and strengthening of Parisian potential research”. The Economics department of Harvard has an (Google Scholar based) $h^{\circ} h$ of 26, Berkeley 21, Yale 17. If we consider all researchers in Management and Economics working in France we get 22 (22 people at least have an h-index greater or equal than 22). We have to concur with Dreze and Estevan (2006): « It is thus clear that emulating Harvard and other top US universities is not within reach for Europe ${ }^{8}$, a fact that I do not regard as dramatic. As suggested above, our eyes should rather be directed to Michigan or Cornell. »

Moreover, too big a concentration might not be desirable as the example of the Cowles foundation

7 The teaching of economics in French universities became independent of the Law curriculum in 1959 only.

$8 \quad$ Needless to say for France alone and in particular in the field of Economics and Management. 
shows. A recent attempt to set up a huge research campus in Social Sciences (“Condorcet campus”) in the north of Paris’ outskirts proved that this kind of concentration was difficult to achieve.

Economics in the USA is living an "Age d'or” even after taking account of what might be termed the Bunuel effect ${ }^{9}$. There are at least 100 scholars in Economics and Management working in USA who are world leaders (h-index above 50 for Google Scholar) in their sub-discipline. In France, only Jean Tirole has an h-index comparable to the index of the best American economists.

\section{Bibliography}

Allais, M. (1974), «Classes Sociales et Civilisations », Economie et Sociétés 43, p. 285-377.

Combes P.-P. and L. Linnemer (2001) « La production d'articles de recherche en économie en France », Annales d'économie et de statistique, 62, p. 5-47.

Coriat Benjamin (2008), "Administration et Financement public de la R\&D et de l'Innovation en France : Présentation et Analyse des Réformes en Cours ", Séminaire CEPN-MSH.

Courtault, J.-M. and N. Hayek (2008), «On the robustness of the h-index: a mathematical approach », Economics Bulletin, Vol. 3, No. 78, 2008 p. 1-9.

Courtault, J.-M., B. Crettez and N. Hayek (2006), «Characterization of Stochastic Dominance for Discrete Random Variables », Working Paper, 10 p.

Drèze, J. and F. Estevan, (2007), « Research and higher education in economics: can we deliver the Lisbon objectives? », Journal of the European Economic Association 5, p. 271-304.

Egghe, L. (2006), « Theory and practice of the g-index », Scientometrics 69 (1), p. 131-152.

Fishburn, P. C. and I. H. Lavalle (1995), "Stochastic dominance on unidimensional grids », Mathematics of Operation Research 20, p. 513-525.

Glänzel, W. (2006), « On the H-index: A mathematical approach to a new measure of publication activity and citation impact », Scientometrics 67 (2), p. 315-321.

Hirsch, J. E. (2005), « An index to quantify an individual's scientific output », Proceedings of the National Academy of science 102 (46), p. 16569-16572.

Lever M. (2006), Grande et petite histoire de la Comédie Française, Fayard.

Méla J.-F. (2009), La Grande-Bretagne réévalue sa réforme de l’évaluation.

White H. (1980), "A heteroskedasticity-consistent covariance matrix, and a direct test for heteroskedasticity », Econometrica 48, p. 721-746.

\footnotetext{
$9 \quad$ Luis Bunuel once said in an interview that for a culture to be recognized internationally it is necessary that the nation be powerful. That Spanish culture is not recognized as Spain continuously lost wars. Hemingway is considered as a major writer as he is American, and Americans are very strong with all their rockets, whereas taken by himself Hemingway is a very ordinary writer.
} 
Annex

Calculations were run during October 2007 until February 2008 for Google Scholar and June 2008 until November 2008 for Scopus.

Table 8 Distribution of the h index

\begin{tabular}{|c|c|c|c|c|c|c|}
\hline \multirow[b]{2}{*}{$\mathrm{h}$} & \multicolumn{3}{|c|}{ Google Scholar } & \multicolumn{3}{|c|}{ Scopus } \\
\hline & Economists & Management & Business Schools & Economists & Management & Business Schools \\
\hline 0 & 515 & 562 & 797 & 1207 & 1396 & 1237 \\
\hline 1 & 454 & 453 & 351 & 343 & 138 & 167 \\
\hline 2 & 354 & 294 & 174 & 132 & 44 & 82 \\
\hline 3 & 200 & 137 & 93 & 57 & 15 & 49 \\
\hline 4 & 112 & 74 & 51 & 37 & 2 & 27 \\
\hline 5 & 51 & 39 & 41 & 28 & 0 & 16 \\
\hline 6 & 36 & 17 & 30 & 6 & 1 & 19 \\
\hline 7 & 24 & 8 & 21 & 7 & 1 & 11 \\
\hline 8 & 18 & 6 & 19 & 2 & 1 & 11 \\
\hline 9 & 10 & 5 & 12 & 2 & 0 & 5 \\
\hline 10 & 12 & 1 & 7 & 2 & 1 & 2 \\
\hline 11 & 12 & 3 & 11 & 3 & 1 & 0 \\
\hline 12 & 5 & 0 & 5 & 1 & 0 & 2 \\
\hline 13 & 3 & 0 & 5 & 1 & 1 & 1 \\
\hline 14 & 6 & 0 & 2 & 1 & 0 & 1 \\
\hline 15 & 5 & 0 & 2 & 0 & 0 & 1 \\
\hline 16 & 2 & 0 & 1 & 0 & 0 & 0 \\
\hline 17 & 0 & 1 & 4 & 0 & 0 & 2 \\
\hline 18 & 2 & 0 & 1 & 0 & 0 & 0 \\
\hline 19 & 2 & 0 & 0 & 0 & 0 & 0 \\
\hline 20 & 1 & 1 & 4 & 0 & 0 & 0 \\
\hline 21 & 0 & 0 & 0 & 0 & 0 & 1 \\
\hline 22 & 1 & 1 & 1 & 0 & 0 & 1 \\
\hline 23 & 1 & 0 & 0 & 0 & 0 & 0 \\
\hline 24 & 1 & 0 & 1 & 0 & 0 & 0 \\
\hline 25 & 0 & 0 & 0 & 0 & 0 & 0 \\
\hline 26 & 1 & 0 & 1 & 0 & 0 & 0 \\
\hline 27 & 0 & 0 & 0 & 0 & 0 & 0 \\
\hline 28 & 0 & 0 & 1 & 0 & 0 & 0 \\
\hline 29 & 1 & 0 & 1 & 0 & 0 & 0 \\
\hline$[30,37]$ & 0 & 0 & 0 & 0 & 0 & 0 \\
\hline 38 & 0 & 0 & 1 & 0 & 0 & 0 \\
\hline & 1829 & 1602 & 1637 & 1829 & 1601 & 1635 \\
\hline
\end{tabular}

